\title{
Association of myocardial infarction with stressful life events and psychiatric symptoms: a population- based survey
}

Z.N. Hatmi, ${ }^{1}$ L.F. Nasiri, ${ }^{2}$ Z. Sadegianmehr, ${ }^{2}$ S. Mirkia ${ }^{2}$ and S. Darbooy ${ }^{2}$

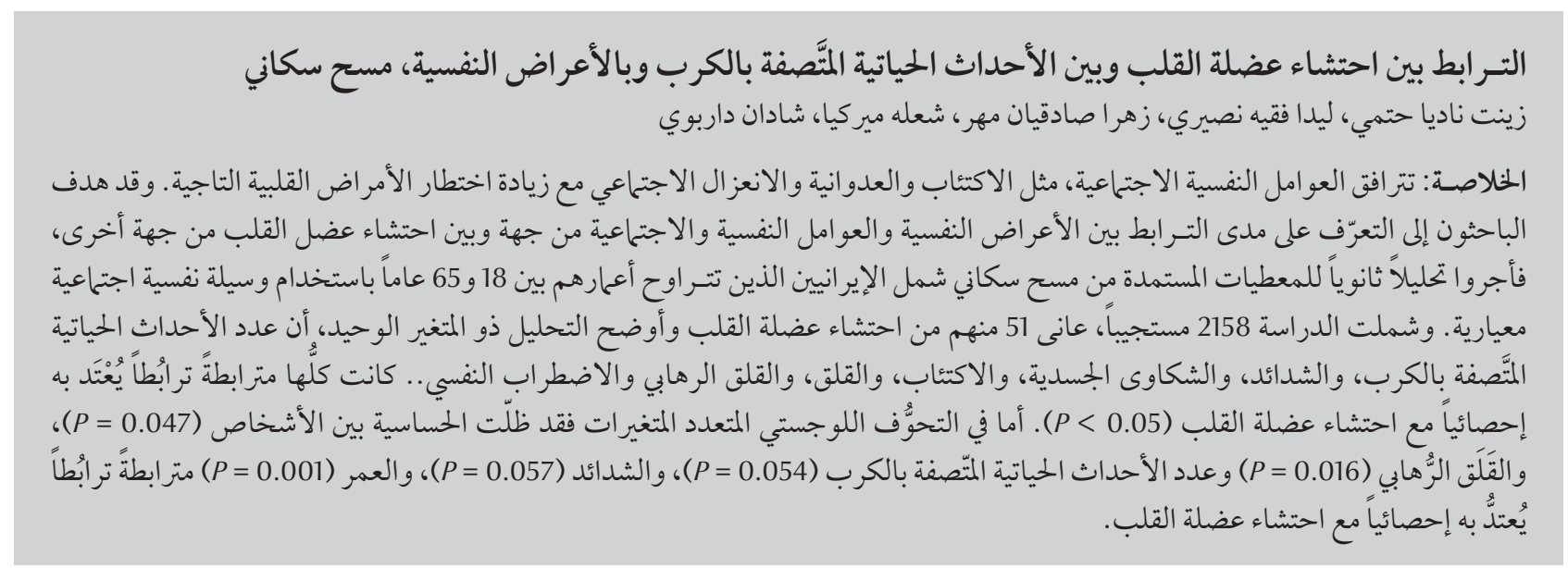

ABSTRACT Psychosocial factors such as depression, hostility, social isolation are associated with increased risk of coronary heart disease. We aimed to determine the association of psychiatric symptoms and psychosocial factors with myocardial infarction (MI). We performed a secondary analysis of data from a population-based survey of Iranians aged 18-65 years using standardized psychosocial instruments. Of the 2158 participants, 51 had suffered an MI. In univariate analysis: number of stressful life events, stressfulness, somatization, depression, anxiety, phobic anxiety and psychoticism were significantly associated with $\mathrm{MI}(P<0.05)$. In multivariate logistic regression, interpersonal sensitivity $(P=0.047)$, phobic anxiety $(P=0.016)$, number of stressful life events $(P=$ $0.054)$, stressfulness $(P=0.057)$ and age $(P=0.001)$ remained at significantly associated with MI.

Association de l'infarctus du myocarde aux événements de vie stressants et aux symptômes psychiatriques : une enquête en population générale

RÉSUMÉ Les facteurs psychosociaux tels que la dépression, I’hostilité et l'isolement social sont associés à un risque accru de coronaropathie. Nous avons cherché à déterminer l'association entre les symptômes psychiatriques, les facteurs psychosociaux et l'infarctus du myocarde. Nous avons réalisé une analyse secondaire des données issues d'une enquête en population générale auprès d'Iraniens âgés de 18 à 65 ans, au moyen d'instruments psychosociaux standardisés. Parmi les 2158 participants, 51 avaient souffert d'un infarctus du myocarde. Dans une analyse univariée, le nombre d'événements de vie stressants, le degré de stress, la somatisation, la dépression, I'anxiété, l'anxiété phobique et le psychoticisme étaient significativement associés à l'infarctus du myocarde $(P<0,05)$. Dans une analyse de régression logistique multivariée, la sensibilité interpersonnelle $(P=0,047)$, l'anxiété phobique $(P=0,016)$, le nombre d'événements de vie stressants $(P=0,054)$, le degré de stress $(P=0,057)$ et l'âge $(P=0,001)$ étaient aussi fortement associés à l'infarctus du myocarde.

'Medical Faculty, Tehran University ofMedical Sciences, Tehran, Islamic Republic of Iran (Correspondence to Z.N. Hatmi: znhatmi@yahoo.com; hatmizn@sina.tums.ac.ir).

${ }^{2}$ Tehran University of Medical Sciences, Tehran, Islamic Republic of Iran.

Received: 24/08/2009; accepted: 11/11/2009 


\section{Introduction}

Psychosocial factors including depression, chronic hostility, social isolation and lack of social support, have been associated with increased risk of coronary heart disease (CHD) [1].

Both mental and clinical stress can increase vascular risk [2]. Adrenergic stimulation during mental stress can cause coronary vasoconstriction and interfere with the myocardial oxygen supply [2]. Furthermore, other studies have shown that mental stress can cause platelet and endothelial dysfunction, metabolic syndrome and induction of ventricular arrhythmias [2].

An association has been reported between cynical hostility and cardiovascular mortality after adjusting for demographic, lifestyle, and physiological variables. [3]. Clinical depression has also been shown to be significantly associated with $\mathrm{CHD}$ [2]. In a meta-analysis of 11 cohort studies, clinical depression was a stronger predictor of coronary disease (risk ratio $=2.7$ ) than depression mood (risk ratio $=1.5$ ) [2].

In addition, acute stress related to natural disasters has been reported to be a risk factor for acute coronary events [2]. Work-related stress and anger have also been recognized as a vascular risk [2].

In the INTERHEART study, where psychosocial factors were evaluated with 4 simple question about work, home, financial stress and major life events in the past year, psychosocial stressors significantly increased the risk of acute myocardial infarction (MI) [4]. Hostility and time urgency/impatience have been found to be significantly associated with long-term risk of hypertension [5].

To shed light on the relation between recent (in the past 6 months) and earlier (in the 6 months prior to that) stressful life events and psychological distress with MI, we performed a secondary analysis of data collected during a population-based survey of 2158 people using standardized psychosocial instruments such as SCL-90 and the Paykel stressful life event questionnaire [6-8].

\section{Methods}

\section{Study design}

A population-based cross-sectional study was designed [7]. Sampling method was two-stage random sampling. In the first stage 5 districts out of 8 districts located in the area of the research centre were selected by simple random sampling. In the second stage, 2158 people aged $18-65$ years living in the 5 centres were recruited to the study by systematic random sampling. The outcome measure was history MI in the past 6 months.

Informed, verbal consent was obtained from the participants at entry to the survey.

\section{Questionnaires}

We have provided the information with regard to psychometric properties of the translated instruments in the original Farsi paper [7].

Participants were interviewed about recent life events to assess the stressful life events in the past 6 months and in the 6 months prior to that, and the degree of stress they induced.

SCL-90-R was used to evaluate psychiatric symptoms. The 90 items of the SCL-90-R are on a 5-point Likert scale; participants were asked to respond within a 4 weeks time period. The Global Severity Index (GSI) cut-off point equal to 0.7 was used for detection of psychiatric illness using the SCL-90-R questionnaire [9].

A validated questionnaire was used to record demographic variables and past medical history of the study participants. The demographic questionnaire was validated by the researchers. Content validity was confirmed by professional, internal consistency of the items was confirmed by Cronbach alpha of 0.82 . The reliability of the questionnaire was examined bya test-retest process and a correlation coefficient of 0.80 was obtained

\section{Statistical analysis}

Statistical analysis was carried out using SPSS, version 13.

The Pearson chi-squared test, independent sample t-test, and ANOVA were used for univariate analysis to determine the relationship between stressful life events, psychotic symptoms and demographic variables with myocardial infarction.

Logistic regression analysis was carried out to evaluate multivariate associations between MI and stressful life events and psychiatric symptoms, adjusting for demographic and other coronary artery disease (CAD) risk factors.

\section{Results}

Baseline characteristics of the participants are shown in Table 1. Of the 2158 participants, 51 had suffered an MI (2.4\%). Those who had suffered an MI were significantly older than those who had not [48.15 (SD 12.53) years versus 32.81 (SD 12.22) years respectively] ( $P$ $<0.001)$. Those suffering an MI were also significantly less educated $(P<$ 0.001 ) but sex, marital status and occupation were not significantly associated with MI.

Table 1 also shows the stress factors of MI cases compared with non-MI participants. The number of stressful life events, the degree of stressfulness and the global severity index were all significantly higher in MI cases.

Table 2 shows the psychiatric symptoms measured by the SCL-90-R inventory in participants suffering $\mathrm{MI}$ versus those who had no suffered an MI. Those who suffered an MI scored significantly higher than non-MI participants for obsessive-compulsive 


\begin{tabular}{|c|c|c|c|}
\hline \multirow[t]{2}{*}{ Variable } & MI cases $(n=51)$ & Non MI cases $(n=2107)$ & \multirow{2}{*}{$P$-level } \\
\hline & $\%$ & $\%$ & \\
\hline Age (years) [mean (SD)] & $48.15(12.53)$ & $32.81(12.22)$ & 0.001 \\
\hline \multicolumn{4}{|l|}{$\operatorname{Sex}$} \\
\hline Female & 56.9 & 55.5 & \multirow[t]{2}{*}{0.46} \\
\hline Male & 43.1 & 44.5 & \\
\hline \multicolumn{4}{|l|}{ Education } \\
\hline Primary school & 72.5 & 28.4 & \multirow{4}{*}{0.001} \\
\hline Pre-high school & 21.6 & 23.9 & \\
\hline High school & 3.9 & 38.3 & \\
\hline University & 2.0 & 9.3 & \\
\hline \multicolumn{4}{|l|}{ Occupation } \\
\hline Housewife & 52.9 & 40.0 & \multirow{4}{*}{0.44} \\
\hline Worker & 7.8 & 8.6 & \\
\hline Administrative worker & 13.7 & 12.6 & \\
\hline Self employed & 21.6 & 17.0 & \\
\hline \multicolumn{4}{|l|}{ Marital status } \\
\hline Single & 5.9 & 30.8 & \multirow{4}{*}{0.06} \\
\hline Married & 86.3 & 65.9 & \\
\hline Widow & 5.9 & 2.3 & \\
\hline Divorced & 2.0 & 1.0 & \\
\hline No. of stressful life events (O-22) [Mean (SD)] & $4.8(0.50)$ & $4.17(3.26)$ & 0.005 \\
\hline Stressfulness (O-402) [Mean (SD)] & $71.74(64.43)$ & $57.29(51.67)$ & 0.004 \\
\hline Global severity index (O-3.57) [Mean (SD)] & $0.94(0.68)$ & $0.73(0.59)$ & 0.006 \\
\hline
\end{tabular}

$M I=$ myocardial infarction $; S D=$ standard deviation .

symptoms, depression, anxiety, phobic anxiety and psychoticism. Somatization, interpersonal sensitivity, hostility, paranoid ideation and other psychiatric symptoms were not associated with MI.
The relationship of psychiatric illness using the GSI cut-off point of 0.7 for SCL-90-R with MI is shown in Table 3. The likelihood of psychiatric illness in those with MI versus those without was significantly higher for all primary symptom dimensions except hostility.

Table 4 presents the relationship between MI and experiencing

\begin{tabular}{lccc}
\hline Table 2 Psychiatric symptoms measured by SCL-90-R inventory in participants suffering MI versus without MI & \\
\hline Symptom & MI cases $(\boldsymbol{n}=\mathbf{5 1})$ & Non MI cases $(\boldsymbol{n}=\mathbf{2 1 0 7})$ & $\boldsymbol{P}$-level \\
& Mean (SD) & Mean (SD) & 0.01 \\
Somatization & $14.92(10.08)$ & $9.52(8.36)$ & 0.06 \\
Obsessive compulsive & $9.76(7.62)$ & $7.99(6.79)$ & 0.60 \\
Interpersonal sensitivity & $7.21(6.39)$ & $6.76(6.11)$ & 0.03 \\
Depression & $13.78(10.76)$ & $10.79(9.80)$ & 0.013 \\
Anxiety & $9.50(8.59)$ & $7.07(6.76)$ & 0.59 \\
Hostility & $4.52(4.17)$ & $4.21(4.16)$ & 0.01 \\
Phobic anxiety & $4.68(4.3)$ & $2.74(1.36)$ & 0.23 \\
Paranoid ideation & $7.25(5.03)$ & $6.39(5.07)$ & 0.03 \\
Psychoticism & $6.66(6.11)$ & $4.96(3.57)$ & 0.22 \\
Other & $6.88(5.21)$ & $6.09(5.02)$ & \\
\hline
\end{tabular}

${ }^{a}$ Other includes disturbance in appetite and sleep patterns.

$M I=$ myocardial infarction $; S D=$ standard deviation . 


\begin{tabular}{lcc}
\hline $\begin{array}{l}\text { Table } 3 \text { Likelihood of psychiatric illness (GSI cut-off point }=\mathbf{0 . 7} \text { for SCL-90-R) in } \\
\text { those suffering MI (51 participants) versus those without } \mathbf{M I} \text { (2107 }\end{array}$ participants) \\
\hline Psychiatric caseness & Likelihood ratio & P-value \\
Somatization & 75.19 & 0.001 \\
Obsessive-compulsive & 48.77 & 0.008 \\
Interpersonal sensitivity & 33.10 & 0.001 \\
Depression & 69.70 & 0.001 \\
Anxiety & 45.70 & 0.001 \\
Hostility & 21.90 & 0.23 \\
Phobic anxiety & 26.82 & 0.001 \\
Paranoid ideation & 42.78 & 0.001 \\
Psychoticism & 35.63 & 0.001 \\
Other & 31.64 & 0.11 \\
\hline
\end{tabular}

MI = myocardial infarction .

stressful life events. Four events in the past 6 months and 3 other events in the 6 months prior to that were significantly associated with MI. All of the other items that were in the Paykel questionnaire were not found to be significantly associated.

In a logistic regression analysis to determine the factors significantly associated with MI while controlling for confounding of the variables, the following variables remained significantly associated with MI: interpersonal sensitivity $(P=0.047)$, phobic anxiety $(P=0.016)$, stressful life events count $(P=0.054)$, degree of stressfulness $(P=0.057)$ and age $(P=0.001)$ (Table 5).

\section{Discussion}

In our study, the number of stressful life events in the past 6 months and in the 6 months prior to that, degrees of stressfulness, interpersonal sensitivity and phobic anxiety were statistically significant associated with myocardial infarction in the past 6 months.

Previous research has shown the increased risk of vascular effects, $\mathrm{CHD}$ and acute MI with mental stress and INTERHEART study, psychosocial factors were evaluated using a series of simple questions and the status of stress and depression were self-reported. In our study, however, we evaluated the stress status and psychiatric symptoms psychiatric stressors $[1,2,4]$. In the using standardized, detailed stressful life events and the SCL-90-R inventory. In these 2 questionnaires, definitions and measurements of psychosocial factors are more precise and validated. These instruments are known to be more useful for population based studies [7]. A recent study demonstrated the particular usefulness and application of the SCL-90-R inventory in CAD, both acute events and chronic $\mathrm{CAD}$ [10].

The role of clinical depression in the development of CAD has been reported recently $[2,11]$; in our investigation we found a statistically significant association between depression and MI in the univariate analysis, with a likelihood ratio of relation between $\mathrm{MI}$ and depression of $69.70(P=0.001)$. Temporal relationship between $\mathrm{CAD}$ and clinical depression has been reported previously where clinical depression appeared to be an independent risk factor for developing CAD rather than a co-morbid condition [11].

In our study the number of stressful life events in the past 6 months and in the 6 months before that was significantly associated with MI $(P=0.005)$. This finding does not concur with that of Moller et al. reported in 2005 [12], who found that sudden, shortterm work-related stressful events in a Swedish population were associated with myocardial infarction. However,

\begin{tabular}{|c|c|c|c|}
\hline \multirow[t]{2}{*}{ Event } & MI cases $(n=51)$ & Non MI cases $(n=2107)$ & $P$-value ${ }^{\text {a }}$ \\
\hline & No. (\%) & No. (\%) & \\
\hline \multicolumn{4}{|l|}{ In the past 6 months } \\
\hline Retirement & $13(25.49)$ & $146(6.92)$ & 0.031 \\
\hline Bombardment (city attacked) & $4(7.84)$ & $53(2.51)$ & 0.001 \\
\hline Emigration (outside) & $4(7.84)$ & $205(9.72)$ & 0.001 \\
\hline \multicolumn{4}{|l|}{ Prior to the 6 months } \\
\hline Change in financial state & $8(15.68)$ & $138(6.0)$ & 0.009 \\
\hline Child leaving home & $7(13.72)$ & $48(2.27)$ & 0.009 \\
\hline Detention/arrest & $13(25.49)$ & $140(6.64)$ & 0.033 \\
\hline Spouse left home after an argument & $10(19.60)$ & $111(5.26)$ & 0.038 \\
\hline
\end{tabular}

${ }^{a}$ Pearson $\chi^{2}$ test or Fisher exact test.

$M I=$ myocardial infarction . 


\begin{tabular}{lcccc}
\hline \multicolumn{4}{l}{ Table 5 Factors significantly associated with myocardial } & infarction using logistic regression analysis \\
\hline Parameter & Wald test & $\boldsymbol{P}$-value & Odds ratio & 95\% confidence interval \\
Interpersonal sensitivity & 3.93 & 0.047 & 2.56 & $1.02-6.66$ \\
Phobic anxiety & 5.75 & 0.016 & 2.29 & $1.16-4.52$ \\
Number of stressful life events & 3.71 & 0.054 & 10.00 & $1.04-100$ \\
Degree of stressfulness & 3.63 & 0.057 & 2.43 & $1.01-6.06$ \\
Age & 18.74 & 0.001 & 1.07 & $1.04-1.11$ \\
\hline
\end{tabular}

they found no evidence that an accumulation of stressful life events over a period of 12 months increased the risk of myocardial infarction. In our investigation, we evaluated a different number of stressful life events before and after 6 months using a standardized instrument with a wide range of life events so we can demonstrate the broader aspects of the problem. In addition, the degree of stressfulness of life events in the past 6 months and in the 6 months before that were statistically significantly different between MI cases and non cases ( 71.74 versus 57.29 respectively, $P=0.004)$. Earlier studies have concluded that work-related life events, particularly those with any work load, were significantly associated with the risk of MI $[12,13]$. We found that change in financial state, spouse leaving home, son or daughter leaving home and detention/arrest in the past 6 months, and retirement, emigration and bombardment (of the city) in the 6 months before that were significantly associated with MI.
When we used the GSI cut-off point equal to 0.70 for detection of psychiatric illness in the SCL-90-R questionnaire, we found phobic anxiety and interpersonal sensitivity were significantly associated with MI

This was a cross-sectional study and can only assess associations and has limitations in terms of temporality and determining cause-effect relationship. These limitations might be overcome in a prospective concurrent cohort study, considering conventional and novel risk factors of CAD [14-19]. In spite of the limitations, the advantages of present research are: i) it was population based with random selection which allows the results to be generalized to the reference population; ii) standardized and well-known instruments were used for detection of the events and symptoms.

In conclusion, our study showed that psychosocial factors including number of stressful life events, degree of stressfulness, interpersonal sensitivity and phobic anxiety were significantly associated with MI.

Psychotic symptoms at the community level have been recognized with different patterns and severity. Socioeconomic status and social stressors are related to the prevalence and severity of psychotic symptoms. The prevalence and severity of psychotic symptoms in our study population, which was a dense urban community with low socioeconomic status, was very high. There is a need therefore to address this high level of psychiatric symptoms and consequent clinical psychiatric and psychosomatic disorders in order to reduce the risk of associated MI.

\section{Acknowledgements}

This project was supported by a grant from the Tehran University of Medical Sciences. The authors wish to sincerely thank Dr Mohammad Effatpanah and Dr Mehdi Mirsharifa for their contributions.

\section{References}

1. Gaziano JM, Manson JE, Ridker PM. Primary and secondary prevention of coronary heart disease. In: Libby P et al. Braunwald's heart disease: a textbook of cardiovascular medicine. Philadelphia, Saunders Elsevier, 2008.

2. Ridker PM, Libby P. Risk factors for atherothrombotic disease. In: Libby P et al. Braunwald's heart disease: a textbook of cardiovascular medicine. Philadelphia, Saunders Elsevier, 2008.

3. Iribarren $\mathrm{C}$ et al. Association of hostility with coronary artery calcification in young adults: the CARDIA study. Coronary Artery Risk Development in Young Adults. Journal of the American Medical Association, 2000, 283:2546-2551.

4. Rosengren A et al.; INTERHEART investigators. Association of psychosocial risk factors with risk of acute myocardial infarction in 11119 cases and 13648 controls from 52 countries (the INTERHEART study): case-control study. Lancet, 2004, 364:953-962.
5. Yan LL et al. Psychosocial factors and risk of hypertension: the Coronary Artery Risk Development in Young Adults (CARDIA) study. Journal of the American Medical Association, 2003, 290:2138-2148.

6. Sharifi V. Urban mental health in Iran: Challenges and future directions. Iranian Journal of Psychiatry and Behavioral sciences, (IJPBS), 2009, 3(1):9-14.

7. Faghih Nasiri L et al. Prevalence of stressful factors and psychiatric symptoms among individuals under the care of Aboozar health and medical center. Advances in Cognitive Science, 2006, 8(1):47-53.

8. Rossler W et al. Psychotic experiences in the general population :A twenty-year prospective community study. Schizophrenia Research, 2007, 92:1-14.

9. Holi MM, Marttunen M, Aalberg V. Comparison of the GHQ36 , the GHQ-12 and the SCL-90 R as psychiatric screening 
instruments in the Finnish population. Nordic Journal of Psychiatry, 2003, 57(3):233-238.

10. Croft A. The SCL-90-R in clinical application. Dynamic chiropractic, 1999, 17(10):1-8.

11. Zellweger MJ et al. Coronary artery disease and depression. European Heart Journal, 2004, 25:3-9.

12. Möller J et al. Work related stressful life events and the risk of myocardial infarction. Case-control and case-crossover analyses within the Stockholm heart epidemiology programme (SHEEP). Journal of Epidemiology and Community Health, 2005, 59:23-30.

13. Theorell T, Floderus-Myrhed B. 'Workload' and risk of myocardial infarction-a prospective psychosocial analysis. International Journal of Epidemiology, 1977, 6:17-21.

14. Hackam DG, Anand SS. Emerging risk factors for atherosclerotic vascular disease: a critical review of the evidence. Journal of the American Medical Association, 2003, 290:932-940.
15. Morgan TM et al. Nonvalidation of reported genetic risk factors for acute coronary syndrome in a large-scale replication study. Journal of the American Medical Association, 2007, 297:1551-1561.

16. Whooley MA. Depression and cardiovascular disease: healing the broken-hearted. Journal of the American Medical Association, 2006, 295:2874-2881.

17. Blumenthal JA et al. Effects of exercise and stress management training on markers of cardiovascular risk in patients with ischemic heart disease: a randomized controlled trial. Journal of the American Medical Association, 2005, 293:1626-1634.

18. Frasure-Smith N, Lespérance F. Depression-a cardiac risk factor in search of a treatment. Journal of the American Medical Association, 2003, 289:3171-3173.

19. Boekholdt SM et al. C-reactive protein levels and coronary artery disease incidence and mortality in apparently healthy men and women: the EPIC-Norfolk prospective population study 1993-2003. Atherosclerosis, 2006, 187:415-422.

\section{The First Global Conference on Healthy Lifestyles and Noncommunicable Diseases Control}

The First Global Ministerial Conference on Healthy Lifestyles and Noncommunicable Disease Control was held in Moscow, Russian Federation from 28 to 29 April 2011. This conference is a key milestone in the international campaign to curb the impacts of cancers, cardiovascular diseases, diabetes and chronic lung diseases.

Convened by the Russian Federation and the World Health Organization (WHO), the Conference aimed to help Member States develop and strengthen policies and programmes on healthy lifestyles and noncommunicable disease prevention. These efforts are based on the Global strategy for the prevention and control of NCDs and its action plan.

The Moscow event will feed into the 19-20 September, 2011, United Nations General Assembly High-level Meeting on the Prevention and Control of Noncommunicable Diseases.

Information about noncommunicable diseases in the Eastern Mediterranean Region of WHO can be found at http:/ / www.emro.who.int/ncd/. 